V Seminário Anual Científico e Tecnológico | Bio-Manguinhos

\title{
REA 08 - Contribuição ao desenvolvimento e validação de um KIT-QPCR em tempo real para detecção de carbapenemases em sepse por bacilos gram-negativos
}

Marisa Zenaide Ribeiro Gomes ${ }^{1 *}$; Débora Souza Beck ${ }^{1}$; Newton Dias Lourenço²; Stephani da Silva Ribeiro'; Elisangela Martins de Lima²; Karen Yumi Miyashiro²; Caio Augusto Santos Rodrigues²; Saint Clair S. Gomes Junior³; Patrícia Alvarez ${ }^{4}$; Marise Dutra Asensi ${ }^{1}$.

1 IOC / Fiocruz, Laboratório de Pesquisa em Infecção Hospitalar;

2 Hospital Federal Servidores do Estado, Ministério da Saúde;

3 IFF / Fiocruz;

4 Bio-Manguinhos / Fiocruz, Laboratório de Tecnologia Diagnóstica.

\section{Introdução:}

Sepse por bastonetes Gram-negativos (BGN) resistentes aos carbapenemas é uma das principais causas de óbito em unidades intensivas. A detecção precoce de marcadores de resistência bacteriana em amostras clínicas é crucial para guiar a terapia antibiótica e reduzir a mortalidade na sepse.

\section{Objetivo:}

Nesse estudo, a partir dos resultados do protótipo qPCR-KPC2-NDM1, desenvolvido pelo LAPIH/IOC e LATED/Bio-Manguinhos, FIOCRUZ, para a detecção de genes de carbapenemases blaKPC-2 e blaNDM-1 na colônia de BGN, objetivamos avaliar a sua utilização diretamente no sangue total e em hemoculturas positivas e negativas de pacientes com suspeita de sepse, internados em CTI médico-cirúrgico de adultos do Rio de Janeiro. Além disso, investigamos a prevalência de BGNs produtores de carbapenemases em materiais clínicos e de vigilância desses pacientes, visando determinar a melhor combinação de marcadores para o desenvolvimento futuro de um kit específico de detecção de resistência bacteriana em sepse.

\section{Metodologia:}

O BioRobot EZ1 e EASY 1 DNA investigator kit QIAGEN Blood foi utilizado para a extração do DNA bacteriano em sangue. A reação do real time qPCR em ABI 7500 (Applied Biosystems). Entre agosto de 2015 a setembro de 2016 foram enviadas ao LAPIH 1.016 amostras, sendo 692 hemoculturas (401 hemoculturas positivas), 174 
culturas positivas de outros materiais e 150 alíquotas de sangue, identificando-se 261 culturas com BGN, 154 cocos Gram-positivos e 9 fungos.

\section{Resultado:}

Entre 286 isolados de BGN, predominaram Klebsiella pneumoniae (27\%), Pseudomonas aeruginosa (25\%), e Acinetobacter baumannii (17\%). Genes de carbapenemases foram detectados em 35\% (78/220) dos BGNs identificados no LAPIH. blaKPC-2 em 58\% das cepas de K. pneumoniae, enquanto blaOXA-51 e blaOXA-23 em 100\% e $84 \%$ de cepas de A. baumannii, respectivamente. Em P. aeruginosa apenas 5\% teve blaKPC-2 e 1,5\% de blaOXA-48. blaSPM-1 e blaNDM-1 não foram identificados. Quanto aos resultados do protótipo, de 83 hemoculturas avaliadas inicialmente, sendo 41 alíquotas em "pools" coletadas no mesmo momento de mesmo paciente, todas as hemoculturas positivas para KPC-2 ( $\mathrm{n}=9$ ) por cultura e PCR convencionais (padrão ouro) foram também positivas para este gene e amplificaram 16S-RNA pelo qPCR. Seis hemoculturas positivas não KPC-2 $(26 \%, 6 / 23)$ amplificaram 16SRNA. Enquanto, 5 hemoculturas negativas (14\%, 5/37) amplificaram 16SRNA. Não houve amplificação de blaNDM-1. Todas as amostras de sangue total analisadas $(\mathrm{n}=14)$ apresentaram $\mathrm{Ct}$ 's elevados, provavelmente pela baixa concentração de DNA bacteriano. Desse modo, qPCR-KPC2-NDM1 apresentou 100\% e $83 \%$ de sensibilidade e $100 \%$ e $87 \%$ de especificidade para a detecção de blaKPC-2 e 16SRNA em hemoculturas, respectivamente.

\section{Conclusão:}

Elevada prevalência de BGN produtor de carbapenemases em pacientes com sepse foi observada, e esses resultados indicam a incorporação de OXA-51 e/ ou OXA-23 ao protótipo desenvolvido. Os resultados preliminares são bastantes promissores para o desenvolvimento de um multiplex qPCR específico e fundamental para a melhoria do prognóstico em sepse por BGN em pacientes críticos.

\section{Palavras-chave: Sepse; Bactéria Gram-negativa; Carbapenemase}

